\title{
Evidence for direct solar control of the mesopause dynamics through dayglow and radar measurements
}

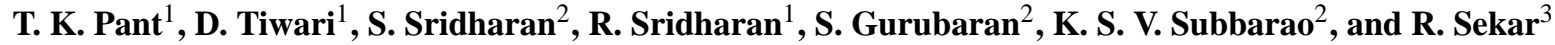 \\ ${ }^{1}$ Space Physics Laboratory, VSSC, Thiruvananthapuram-22, India \\ ${ }^{2}$ Equatorial Geophysical Research Laboratory, Tirunelveli, India \\ ${ }^{3}$ Physical Research Laboratory, Ahmedabad, India
}

Received: 22 August 2003 - Revised: 21 January 2004 - Accepted: 11 February 2004 - Published: 23 September 2004

Part of Special Issue "Equatorial and low latitude aeronomy"

\begin{abstract}
The day-to-day measurements of the daytime intensities of hydroxyl $(\mathrm{OH})$ Meinel (8-3) band airglow emissions at 731.6 and $740.2 \mathrm{~nm}$ carried out from the equatorial station Thiruvananthapuram $\left(8.5^{\circ} \mathrm{N}, 76.5^{\circ} \mathrm{E}, 0.5^{\circ} \mathrm{dip}\right)$ during the period of January-March 2001 have been investigated. This investigation provides evidence for the presence of a long period $(\approx 16$ days) wave modulating these intensities at the mesopause altitudes. Simultaneous radar measurements of zonal wind at $\sim 87 \mathrm{~km}$, i.e. mesopause from Tirunelveli $\left(8.7^{\circ} \mathrm{N}, 77.8^{\circ} \mathrm{E}, 0.33^{\circ} \mathrm{dip}\right)$, a location nearby, also reveal the presence of these long period oscillations. The daytime airglow and zonal wind undergo changes simultaneously. Similar modulations are seen in the solar $10.7 \mathrm{~cm}$ flux also preceding dayglow and wind variabilities by $4-5$ days. It is inferred in the present case that the changes in the solar flux are the cause of the generation of this long period wave in the atmosphere below the mesosphere. The oscillations in the measured dayglow intensities in the mesopause region and the winds at $\sim 87 \mathrm{~km}$ are resulting from the modulation caused by this wave in this region after a delay of 4-5 days.
\end{abstract}

Key words. Meteorology and atmospheric dynamics (waves and tides)

\section{Introduction}

The understanding of the aeronomy at and around the mesopause altitudes has significantly improved in the last decade. The relative inaccessibility of the upper mesosphere/lower thermosphere regions $(\sim 80-100 \mathrm{~km})$ to the traditional probing techniques has been overcome due to a remarkable improvement in the ground-based techniques, such as the optical photometry and spectrometry of various airglow emissions originating in this region. Selected emission lines of hydroxyl $(\mathrm{OH})$ and Oxygen $\left(\mathrm{O}_{2}\right)$ molecules are commonly used for inferring the physical processes. These

Correspondence to: R. Sridharan

(r_sridharan@vssc.org) emission intensities have been used to indirectly estimate the ambient temperature of the altitude regions from where the airglow emanates, for example, around $\sim 87 \mathrm{~km}$ in the case of OH (Krassovsky, 1972). Studies concerning these emissions have brought forth some new findings not only regarding the upper- mesosphere, lower-thermosphere chemistry, but also on the propagation characteristics of internal gravity waves and planetary waves (Taylor et al., 1991; Sivjee, 1992). Analyses of long time series of measurements on $\mathrm{OH}$ airglow intensity and estimated mesopause temperature at various locations on the globe, particularly during nighttime, have revealed the presence of the planetary wave induced long period oscillations therein; Takahashi et al. (2002) and references therein.

Over the equatorial latitudes, these oscillations of periods between $\sim 2$ to 16 days become quite important, as these are believed to be of global scale and are generally ascribed to planetary waves that exhibit unique propagation characteristics in the mesosphere, the lower-thermosphere and the ionosphere (MLTI) (Salby, 1984; Forbes, 1995). Extra long periods, i.e. 20-40 day oscillations in the mesospheric and lower thermospheric winds, have also been reported recently (Luo et al., 2000, 2001 and the references therein). However, the propagation characteristics of these planetary waves above $\sim 80 \mathrm{~km}$ are not yet well understood. It is known that the energetics and the dynamical state prevailing in the regions through which they propagate would significantly modify the characteristics of these waves and vice versa. When the various aspects concerning these long and extra long period oscillations in mesospheric parameters, such as wind, are being studied, it is becoming increasingly clear that contrary to the general belief (Ebel et al., 1986), some of these oscillations are a result of the direct solar effect and need not always be due to the presence of planetary waves. In fact, it has been suggested that the solar activity can modulate the existing planetary waves or even trigger wave-like circulation perturbations, through changing radiation fluxes in the middle atmosphere (Luo et al., 2001). 

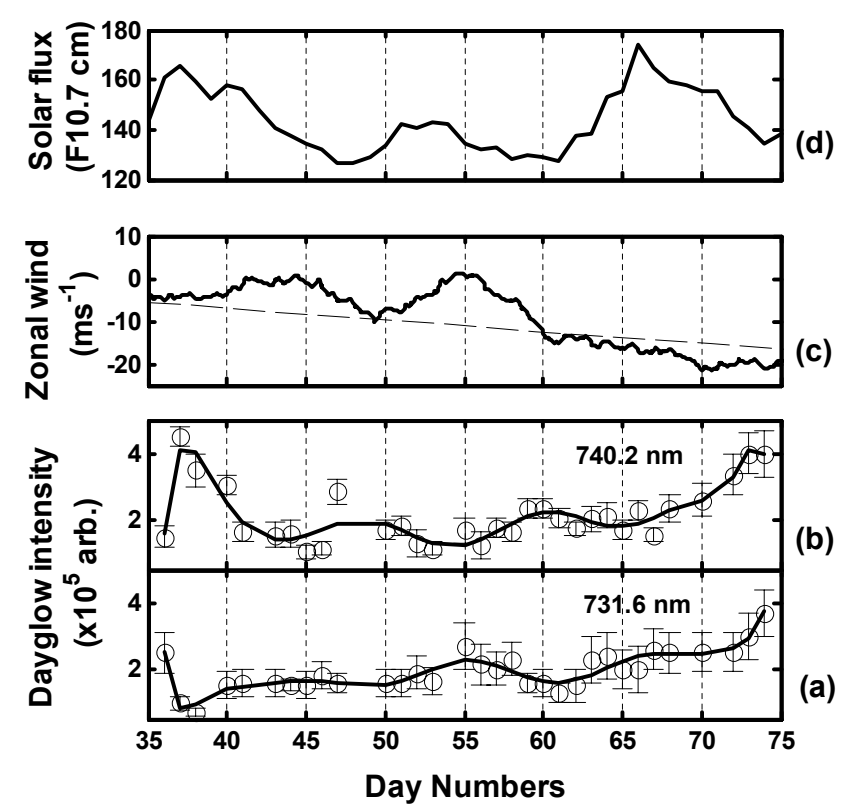

Fig. 1. Top two panels show the day-to-day variation of the mean $\mathrm{F} 10.7 \mathrm{~cm}$ solar flux and the zonal wind velocity with its linear-fit trend, respectively. Bottom two panels show the day-to-day variation of the mean $\mathrm{OH}(8-3)$ dayglow emission intensities at $740.2 \mathrm{~nm}$ and $731.6 \mathrm{~nm}$, including their best-fit curves.

However, this case study conducted using simultaneous measurements of daytime airglow intensity and the zonal wind at mesopause levels over the equator in India reveals that the presence of a planetary wave ( $\sim 16$ day oscillation), owing its existence to solar radiation effects in the atmosphere below the mesopause.

\section{Experimental details}

The daytime airglow intensity measurements were made using Multi Wavelength Dayglow PhotoMeter (MWDPM) on two rotational lines at 731.6 and $740.2 \mathrm{~nm}$ in the $\mathrm{OH}$ Meinel (8-3) band at Thiruvananthapuram $\left(8.5^{\circ} \mathrm{N}, 76.5^{\circ} \mathrm{E}, 0.5^{\circ} \mathrm{dip}\right)$ during January-March 2001 for a period of 47 days. These daytime measurements were made between 08:00 to 18:00 h for zenith sky at every $20 \mathrm{~s}$ interval. Continuous data were available from 35 th to 75 th day of the year.

The details of this photometer have been described earlier (Sridharan et al., 1999 and references therein). In the past, the daytime $\mathrm{OH}$ emission intensity measurements at the wavelengths mentioned above have been successfully used to infer the daytime mesopause temperature. The estimated mesopause temperature using dayglow emission intensities measured by this MWDPM has been validated by comparing with the in situ WINDII satellite measured temperature over a particular longitude in Indian region (Sridharan et al., 1999). This validation was done for two days of measurements at 07:00 and 06:30h, respectively, and could not be extended to other times during the day because of the paucity of simultaneous satellite measurements.

The mesospheric wind measurements were made from another nearby equatorial location, Tirunelveli $\left(8.7^{\circ} \mathrm{N}, 77.8^{\circ} \mathrm{E}\right.$, $0.33^{\circ} \mathrm{dip}$ ), for the same period, by the MF radar operating in the spaced antenna mode. The details of this radar system have been described earlier (Vincent and Lesicar, 1991). The mean solar F10.7 cm indices used in this study were obtained from the World Geophysical Data Center, USA.

\section{Observations}

The variations of the mean daytime airglow emission intensity at the two wavelengths are depicted in Figs. 1 (a, b) as a function of day number. The error bars denote the $1 \sigma$ (standard deviation) variation of the dayglow intensity, on a particular day. A gradual increase is conspicuously seen in the mean dayglow intensity, especially after the 40th day, which is further modulated by a periodic change of an $\sim 12$ 16 day period. Dayglow intensity at both the wavelengths, i.e. 731.6 and $740.2 \mathrm{~nm}$, experience an increase in $\sim 45 \%$ and $33 \%$, respectively, between the 35 th and 75 th day. Moreover, the variabilities at the two $\mathrm{OH}$ dayglow emissions seem to be opposite in phase, except after the 65th day when they appear to be in phase.

The variation of the daily mean $10.7 \mathrm{~cm}$ solar flux during this period is depicted as a function of day number in Fig. 1d. It must be noted that during the period January to March, the solar flux variation exhibits two distinct features; one, a steadily decreasing trend and the other, a modulation with a period of $\sim 16$ days, other than the $\sim 27$-day solar rotation period. In order to facilitate an easy comparison with other measured parameters, the solar flux indices are plotted (Fig. 1d) only between the 35th to 75th day of the year. The mean solar flux decreased by $\sim 9 \%$ between the 35 th to 75 th day. The periodic change in the flux is clearly discernable after the 35th day.

Figure 1c depicts the hourly mean variation of the zonal wind at $\sim 87 \mathrm{~km}$, as measured using the MF radar at Tirunelveli, for the same period. A clear wave-like perturbation is seen in the wind, with the periodicity being $\sim 15-$ 20 days. Similar to the dayglow intensity variations beyond the 65th day, the amplitude of the oscillations in the wind decreases significantly beyond the 60th day.

It is interesting to note that the periodic changes in the airglow intensity at both the wavelengths follow the variations in the solar flux with a time delay of 4-5 days (crosscorrelation coefficient $0.56 \pm 0.35$ for $95 \%$ confidence). The MEM (maximum entropy method) analysis of the dayglow intensities at the two wavelengths and solar flux variability between the 35th and the 75th day reveals that the dominant periodicity with significant power spectral density is around the $\sim 16$ th day or more (Figs. 2 d,c,b). Figure 2 a exhibits the power spectral density corresponding to dominant periodicities present in the measured zonal wind. Along with the presence of long period ( $\sim 12-17$ days) waves, the semidi- 
urnal component in the wind seems to be more prominent than the diurnal mode (inset figure). For clarity, the power spectral density corresponding to periodicities, present in the wind, up to three days is displayed in the inset figure.

Overall, the three independent parameters, i.e. daytime Hydroxyl airglow intensity, zonal wind at $\sim 87 \mathrm{~km}$ and the solar F10.7 cm flux, all having important implications in the dynamics and energetic of the MLTI region, exhibit similar variability seemingly under the influence of a dynamical forcing present in this region. These observations are discussed in the following section, with the perspectives of MLTI energetics and dynamics.

\section{Discussion}

One of the factors that could bring in variations in the ' $\mathrm{OH}$ ' dayglow intensities is the change in the altitude of the $\mathrm{OH}$ emission layer. It has been shown, though the seasonal oscillations and wave influences do vary the altitude of the $\mathrm{OH}$ emission layer, that the extent of variation in the peak emission height never exceeds $\sim 4 \mathrm{~km}$ (Zhang and Shepherd, 1999 and references therein). Further, the width of the emission peak is estimated to be around $\sim 8-10 \mathrm{~km}$, which is much larger than the extent of peak emission height variation. Therefore, the small height variation of the $\mathrm{OH}$ emission layer does not affect the dayglow intensities. Nevertheless, the variabilities induced due to the emission layer movement will exhibit similar trends at both the $\mathrm{OH}$ wavelengths.

In this context, the periodic variations opposite in phase, as seen in the $\mathrm{OH}$ intensity at the two wavelengths in the present study, are due to the relative changes in the population of the excited $\mathrm{OH}^{*}$ which could only be due to the ongoing changes in the energetics. Recent photochemical-dynamical models for the $\mathrm{OH}$ Meinel airglow suggest that these alterations in the energetics are brought about by the advection of excited hydroxyl population by gravity waves, collisional quenching of $\mathrm{OH}^{*}$ and a secondary reaction involving perhydroxyl radical $\left(\mathrm{HO}_{2}\right)$ and $\mathrm{O}$ during daytime (Le-Texier et al., 1989; Vierek and Deehr, 1989; Taylor et al., 1991; Makhlouf et al., 1995). All these factors will result in affecting the vibrational yield of $\mathrm{OH}$. For example, for a given energy if more $\mathrm{OH}^{*}$ levels become populated at lower wavelengths, for example, $731.6 \mathrm{~nm}$, there would be a decrease in the energy available to be shared within remaining $\mathrm{OH}^{*}$ levels, for example, at $740.2 \mathrm{~nm}$ within the same vibration-rotation band. This would manifest itself as opposite changes in the emission intensity of the dayglow at these two wavelengths, as seen in the present case.

Therefore, at the outset, the modulations in airglow intensities at 731.6 and $740.2 \mathrm{~nm}$ in the $\mathrm{OH}(8-3)$. Meinel band, as seen in the present case, appear to be a consequence of the changes in the energetics over long (days and above) time scales. The zonal wind variations at $\sim 87 \mathrm{~km}$ over Tirunelveli for the same period are studied in order to further probe this proposition.

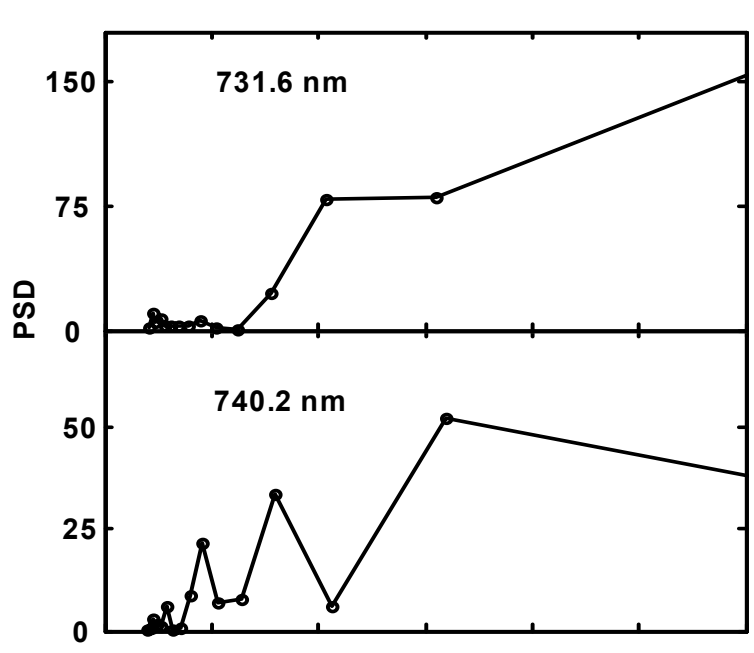

(d)

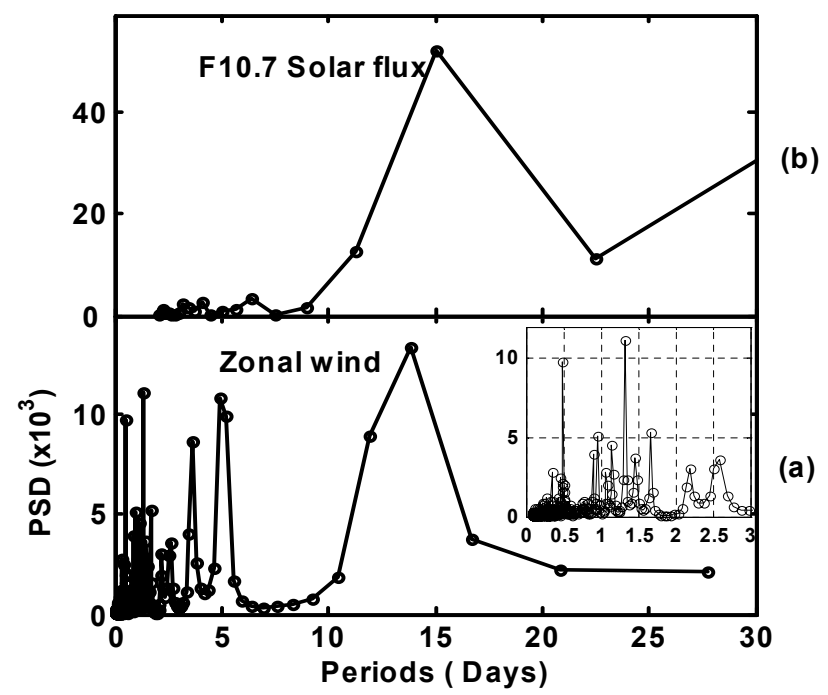

Fig. 2. Top two panels (c) and (d) show the power spectral density distribution of dominant periodicities in the dayglow emission intensity at $740.2 \mathrm{~nm}$ and $731.6 \mathrm{~nm}$, respectively. Panels (a) and (b) exhibit the same for $\mathrm{F} 10.7 \mathrm{~cm}$ solar flux and zonal wind. Inset figure in panel (a) exhibits the power spectral density distribution of periodicities below 3 days in the zonal wind, to highlight that the semidiurnal mode is more dominant than the diurnal mode.

The zonal wind, as mentioned earlier, exhibits a predominantly westward phase modulated by a period of about $\sim 16$ days (Fig. 1c). The westward zonal wind, as seen here, is the consequence of the MSAO. Over Indian longitudes, various studies in the recent past have revealed the presence of a strong mesospheric semiannual oscillation (MSAO) in both zonal and meridional wind components (Rajaram and Gurubaran, 1998 the references therein). Gurubaran and Rajaram (2001) showed, while discussing the climatology of winds over Tirunelveli, that the zonal wind at around mesopause during the equinoctial months is westward and a result of the modulations caused by the mesospheric semiannual oscillation (MSAO). However, for the periodic phases of accelerations and decelerations of the westward wind, as 
seen in the present case (Fig. 1c), a forcing other than MSAO should be responsible. It may be noted that the wind turns almost eastward around day number 45 and 55, which indicates that the momentum due to this additional forcing should be essentially eastward. In the past, phases of intense westward accelerations in mesospheric zonal winds have been seen and explained as resulting from the interaction of diurnal tide with background mean wind (Gurubaran and Rajaram, 2001 and the references therein). As mentioned earlier, the weak diurnal component in comparison to the semidiurnal component in the wind indicates that this interaction is active in this case as well. The power spectral density for the semidiurnal component is almost double that for the diurnal component (inset figure). Further, the wind modulations involving time scales of $\sim 15-20$ days suggest the presence of a planetary wave with eastward momentum in the $\sim 87 \mathrm{~km}$ altitude region during this period. Though the existence of such a wave can be unambiguously established only on the basis of multiple point measurements, the possibility of the wave being originated in the lower atmosphere cannot be negated. A planetary wave originating in the stratosphere and having phase speeds larger than the mean eastward wind speed in this region would show similar characteristics, as it would propagate up without undergoing critical level absorption. The observed eastward momentum of the wave at the mesopause altitudes clearly indicates towards it. It is supported by the fact that the stratopause Semi Annual Oscillation (SSAO) is always out of phase with the MSAO (Garcia et al., 1997), with SSAO being eastward in this case. The exact cause for the time delay of 4-5 days, as seen here, would then correspond to the time taken by the wave to reach the mesopause altitude from the source region. Though the observed time delay could not be established on a more quantitative manner in the present study, it agrees with the observations made by others (e.g. William and Avery, 1992; Jacobi et al. 1998; Beard et al. 2001 and the references therein).

In view of the above, both periodic and linear variations seen in the dayglow intensities seem to be a direct manifestation of the changes in the mesopause energetics through dynamics. Since the mean flow environment at the mesopause is westward, the $\sim 16$-day wave discussed above will be blocked from propagating further upwards, thereby modifying the mean flow itself at this height region and also the energetics therein. The near simultaneous changes in the dayglow intensities along with the wind indicate towards this sort of an interaction. The fact that the extent of variability in the measured intensities significantly reduces after the $\sim 60$ th day completely in accordance with the smaller variabilities in the zonal wind, reiterates this inference. However, the dayglow variabilities at both the wavelengths do not seem to corroborate well with the simultaneous wind variations prior to the 40th day. In the absence of the extended database prior to this day, it is difficult to ascertain the exact cause of these rather fast airglow variabilities.

Further, as mentioned earlier, the solar flux variations also exhibit similar changes that seem to be agreeing with the above mentioned wind phases (cross-correlation coefficient
$0.62 \pm 0.25$ for $95 \%$ confidence for a time delay of $4-5$ days) and the dayglow intensities (Figs. 1c and 1d). This positive correlation and the involved time delay of a few days between the changes in the wind and the solar flux strongly indicates that the variation in the incoming solar radiation and its absorption in the lower atmosphere, perhaps below stratopause, is indirectly contributing to the seeding of these waves.

It has been found that the frequency and amplitudes of these long period waves are strongest in winter and its presence has been detected in $\mathrm{OH}$ temperatures (Espy et al., 1997) and winds (William and Avery, 1992) in the summer mesosphere as well. This has also been theoretically simulated (Forbes et al., 1995). In addition, there have been instances where the observed effects in the upper mesospherelower ionosphere region have been associated with these planetary waves having their origin in the lower atmosphere. For instance, studies of the long-term trends in planetary wave activity ( $\sim 15$ day period), in the ionospheric absorption data clearly reveal these waves as traveling upwards from the lower atmosphere (Lastovicka, 1993 and references therein). High latitude studies of the enhanced ionospheric absorption in the lower atmosphere during winter also indicate upward traveling long period waves causing the observed effects after a time lag of 4-5 days after their generation in the lower stratosphere. In another study investigating the attenuation of equatorial waves, Reddy and Leksmi (1989) show that higher order Kelvin modes of long period can reach the mesosphere with significant amplitudes. Similarly, the presence of these long period waves having their origin in the lower atmosphere have been seen in the low-latitude radio-meteor zone (Pogoreltsev and Sukhanova, 1993).

\section{Conclusions}

Significant long period oscillations ( $\sim 16$ day) in the $\mathrm{OH}$ dayglow intensity and the zonal wind have been observed with a time delay of 4-5 days, following similar variations in the solar flux, as seen in the $10.7 \mathrm{~cm}$ solar flux index. The observed phases of westward deceleration of zonal wind and the $\sim 16$-day period involved, indicate this to be a planetary wave having eastward momentum. This wave seems to have originated in the lower atmosphere, i.e. stratosphere/troposphere, as a consequence of the changes in the solar flux and propagated upwards as the phase of SSAO for this period is eastward. The $\sim 16$-day oscillations seen in the variation of the mean daytime $\mathrm{OH}$ airglow emission intensity at two wavelengths are a manifestation of ongoing changes in the energetics. There is no direct contribution of the solar flux to the observed dayglow variabilities. Nonetheless, for a comprehensive understanding of the climatology of the mesopause dynamics, contribution due to direct forcings, for example, solar-induced and in situ chemistry, and indirect forcing due to short and long period waves originated in the lower atmosphere, are to be properly accounted for in order to fully understand the complex variabilities of the MLTI region. 
Acknowledgements. Topical Editor U.-P. Hoppe thanks K. Shiokawa and another referee for their help in evaluating this paper.

\section{References}

Beard, A. G., Williams, P. J. S., Mitchell, N. J., and Müller, H. G.: A spectral climatology of planetary waves and tidal variability, J. Atmos. Solar-Terr. Phys., 63, 801-811, 2001.

Clemesha, B. R., Takahashi, H., and Batista, P. P.: Mesopause temperatures at $23^{\circ} \mathrm{S}, \mathrm{J}$. Geophys. Res., 95, 7677-7681, 1990.

Ebel, A., Dameris, M., Hass, H., Manson, A. H., Meek, C. E., and Petzoldt, K.: Vertical change of the response to solar activity oscillations with periods around 13 and 27 days in the middle atmosphere, Annales de Geophysicae, A (4), 271-280, 1986.

Epsy, P. J., Stegman, J., and Witt., G.: International variations of the quasi 16-day oscillation in the polar summer mesospheric temperature, J. Geophys. Res., 102, 1983-1990, 1997.

Forbes, J. M., Hagan, M. E., Miyahara, S., Vial, F., Manson, A. H., Meek, C. E., and Portnyagin, Y. I.: Quasi 16-day oscillation in the mesosphere and the lower thermosphere, J. Geophys. Res., 100, 9149-9163, 1995.

Garcia, R. R., Dunkerton, T. J., Lieberman, R. S., Vincent, R. A.: Climatology of the semiannual oscillation of the tropical middle atmosphere, J. Geophys. Res., 102, 26 019-26 032, 1997.

Gurubaran S., and Rajaram, R.: Mean winds, tides and gravity waves during the westward phase of the mesopause semiannual oscillation (MSAO), J. Geophys. Res., 106, 31 817-31 824, 2001.

Jacobi, C., Schminder, R., and Kurscher, D.: Planetary wave activity obtained from long period (2-18 days) variations of mesopause region winds over Central Europe $\left(52^{\circ} \mathrm{N}, 15^{\circ} \mathrm{E}\right), \mathrm{J}$. Atmos. Sol-Terr. Phys., 60, 81-93, 1998.

Krassovsky, V. I.: Infrasonic variations of $\mathrm{OH}$ emission in the upper atmosphere, Ann. Geophys., 28, 739, 1972.

Lastovicka, J.: Planetary wave activity in the upper middle atmosphere inferred from radio wave absorption and the quasibiennial oscillation, Ann. Geophysicae, 11, 820-827, 1993.

Lean, J., van Hoosier, M., Brueckner, G., Prinz, D., Floyd, L., and Edlow, K.: SUSIM/UARS observations of the 120 to 300nm flux variations during the maximum of the solar cycle, Inferences for the 11-year cycle, Geophys. Res. Lett., 19, 2206-2208, 1992.

Le Texier, H., Solomon, S., Thomas, R. J., and Garcia, R. R.: $\mathrm{OH}^{*}(7,5)$ Meinel band dayglow and nightglow measured by the SME limb scanning near infrared spectrometer: Comparison of the observed seasonal variability with two dimensional model simulations, Ann. Geophysicae, 7, 365-374, 1989.

Luo Y., Manson, A. H., Meek, C. E., Meyer, C. K., and Forbes, J. M.: The quasi 16-day oscillations in the mesosphere and lower thermosphere at Saskatoon $\left(52^{\circ} \mathrm{N} 107^{\circ} \mathrm{W}\right)$, J. Geophys. Res., 105, 2125-2138, 2000.
Luo, Y., Manson, A. H., Meek, C. E., Igarashi, K., and Jacobi, Ch.,: Extra long period (20-40 days) oscillations in the mesospheric and lower thermosphereic winds: observations in Canada, Europe and Japan, and considerations of possible solar influences, J. Atmos. Sol. Terr. Phys., 63, 835-852, 2001.

Makhlouf, U. B., Picard, R. H., and Winick, J. R.: Photochemicaldynamical modelling of the measured response of the airglow to gravity waves, basic model for $\mathrm{OH}$ airglow, J. Geophys. Res., 100, 11 289-11311, 1995.

MohanKumar, K.: An investigation on the influence of solar cycle on mesospheric temperatures, Planet. Space Sci., 33, 795-805, 1985.

Pogoreltsev, A. I., and Sukhanova, S. A.: Simulation of the global structure of stationary planetary waves in the mesosphere and lower thermosphere, J. Atmos. Terr. Phys., 55, 33-40,1993.

Rajaram R. and Gurubaran, S.: Seasonal variabilities of lowlatitude mesospheric winds, Ann. Geophys., 16, 197-204, 1998.

Reddy, C. A. and Vijayan, L.: Reflection and attenuation of equatorial waves in the stratosphere and mesosphere, Q. J. R. Meteorol. Soc., 115, 1273-1299, 1989.

Sahai, Y., Giers, D. H., Cogger, L. L., Fagundes P. R., and Garbe, G. P.: Solar flux and seasonal variations of the mesopause temperatures at $51^{\circ}$ N, J. Atmos. Sol.-Terr. Phys., 58, 1927-1934, 1996.

Salby, M. L.: Survey of planetary-scale traveling waves: the state of theory and observations, Rev. Geophys. Space Phys., 22, 209236, 1984.

Sivjee, G. G.: Airglow hydroxyl emissions, Planet. Space Sci., 40, 235-242,1992.

Sridharan, R., Taori, A., Gurubaran, G., Rajaram, R., and Shepherd, M. G.: First results on daytime mesopause $\mathrm{OH}$ rotational temperatures using ground-based photometry from equatorial latitudes, J. Atmos. Sol. Terr. Phys., 61, 15, 1331-1142, 1999.

Takahashi, H., Buriti, R. A., Gobbi, D., and Batista, P. P.: Equatorial planetary wave signatures observed in mesospheric airglow emissions, J. Atmos. Sol. Terr. Phys., 64, 1263-1272, 2002.

Taylor, M. J., Espy, P. J., Baker, D. J., Sica, R. J., Neal, P. C., and Pendleton jr., W. R.: Simultaneous intensity, temperature and imaging measurements of short period wave structure in the $\mathrm{OH}$ nightglow emission, Planet. Space Sci., 39, 1171-1188, 1991.

Viereck, R. A., and Deehr, C. S.: On the interaction between gravity waves and the $\mathrm{OH}$ Meinel (6-2) and the $\mathrm{O} 2$ atmospheric $(0-1)$ bands in the polar night airglow, J. Geophys. Res., 94, 53975404, 1989.

Vincent, R. A. and Lesicar, D.: Dynamics of the equatorial mesosphere: First results with a new generation partial refection radar, Geophys. Res. Lett., 18, 825-828, 1991.

Williams, C. R. and Avery, S. K.: Analysis of long period waves using the mesosphere-stratosphere-troposphere radar at Poker Flat, Alaska, J. Geophys. Res., 97, 20 855-20 861, 1992.

Zhang, S. P., and Shepherd, G. G.: The influence of the diurnal tide on latitudinal distributions of the $\mathrm{O}\left({ }^{1} \mathrm{~S}\right)$ and $\mathrm{OH}$ emission rates observed by WINDII, Geophys. Res. Lett., 26, 529-532, 1999. 